\title{
REINVENTING THE NATIONAL TOPOGRAPHIC DATABASE
}

\author{
A.Jakobsson, R.Ilves ${ }^{\text {a* }}$ \\ ${ }^{a}$ National Land Survey of Finland, P.O.BOX 84, 00521 Helsinki, Finland - (antti.jakobsson, risto.ilves)@nls.fi \\ ISPRS - UN-GGIM Forum
}

KEY WORDS: Topographic Mapping, Core Data, Spatial Data Infrastructure, 3D, 4D, Persistent Identifiers

\begin{abstract}
:
The National Land Survey (NLS) has had a digital topographic database (TDB) since 1992. Many of its features are based on the Basic Map created by M. Kajamaa in 1947, mapping first completed in 1977. The basis for the renewal of the TDB begun by investigating the value of the TDB, a study made by the Aalto University in 2014 and a study on the new TDB system 2030 published by the Ministry of Agriculture in 2015. As a result of these studies the NLS set up a programme for creating a new National Topographic Database (NTDB) in beginning of 2015. First new version should be available in 2019. The new NTDB has following key features: 1) it is based on processes where data is naturally maintained, 2) it is quality managed, 3) it has persistent Ids, 4) it supports 3D,4D, 5) it is based on standards.

The technical architecture is based on interoperable modules. A website for following the development of the NTDB can be accessed for more information: kmtk.maanmittauslaitos.fi.
\end{abstract}

\section{INTRODUCTION}

Topographic Databases produced by national mapping organisations are changing. The main use is no longer making printed maps as it was when for example National Land Survey of Finland (NLS) created the digital version of the basic map in 1992. Today the main use is for location reference as a base map available now through various formats and services.

The use for analysis purposes is also increasing and linking other data with the basic reference. The availability of new data collection methodologies is also chancing the role of the national mapping. Data production is happening everywhere based on different needs. What is needed now is co-ordination and quality assurance for maintaining the national reference information. In this paper we present how the NLS Finland plans to react to this change by introducing the National Topographic Database (NTDB).

\section{USER REQUIREMENTS AND BENEFITS}

\subsection{Need for change}

There have been two dissertations in Finland which relate to the NTDB concept. The first one was on "Multiple Representation and Generalisation of Geo-databases for Topographic Maps" (Kilpeläinen, 1997) and the second one "On the Future of Topographic Base Information Management in Finland and Europe" (Jakobsson, 2006). Kilpeläinen (1997) argued that multiple representation gives flexibility in updating. Jakobsson (2006) suggested the need for harmonized specification, quality management and the need to incorporate municipality data to the national topographic data.

\subsection{Study on value of the TDB}

The basis for the renewal of the TDB begun by investigating the value of the TDB, a study made by the Aalto University in 2014. There were two main parts in this study. First part was the user study on the effects of opening topographic data in Finland. Second part was to find most efficient ways to improve the value of the TDB in future.

\subsubsection{Effects of opening topographic data in Finland}

National Land Survey of Finland made all topographic data available as open data in May 2012. According to the study, there were many totally new topographic data users after opening especially in small enterprises $(41 \%)$ and citizens (60 $\%)$, but also in public sector $(27 \%)$ and large enterprises $(25$ $\%$ ). In total there were 3711 respondents in this study (Mäkelä, 2014).

The main factors influencing to the success of the opening the topographic data were: data is free and open to any use without restrictions and availability of a download service for accessing data easily. They also found some other benefits for users (Ahonen-Rainio et al, 2014):

- Time-saving and reduced costs

- Less field measurements

- Better quality, better planning

- Data use in research and teaching

- New products and services

- Environmental protection

- Better decisions

- More hiking and recreation in nature.

\subsubsection{User requirements}

Main focus in the second part of the study was on improving the value of the TBD. The five main development points were identified (Ahonen-Rainio et al, 2014):

- The TDB and municipalities base data should share a common data model

- $\quad$ Life cycle rules should be introduced

- Better metadata for each feature

- 3D 
- $\quad 24 / 7$ available download and web services.

\subsection{Study on the TDB in 2030}

The Ministry of Agriculture and Forestry made a study on the vision for the national TDB in 2030 (MMM, 2015). In all 74 organizations were interviewed during 2014.

The aim was to increase the usage of the TDB and save costs in production. The co-ordination should still be kept within government but all other options were considered. The main outcomes of the interviews were:

- $\quad$ The TDB and municipalities base data should share a common data model

- The TDB should be interoperable with other public (topographic) data

- Updating may be shared with other organizations (if needed)

- Persistent identifiers should be set for main features

- Not necessary universal classification of land cover

- $\quad 3 \mathrm{D}$ and life cycle rules

- Planning information to be maintained in a separate dataset

- Base information financed by the government

- Data may be charged if massive use within commercial services

- Use conditions may vary

- Separate legislation should be introduced.

\section{THE NTDB CONCEPT}

\subsection{Programme to create the new NTDB}

In 2015 the NLS decided to establish a programme for creating the new National Topographic Database (NTDB). The target for this programme was set for 2019. By then we should have a first new operational system in place.

The changes we seek to introduce are:

- Feature types are critically reviewed. Only needed data should be included. This could mean for example that only basic geometry is included and all other attribute information is kept somewhere else

- The NTDB is considered to be a basic registry and linked with other basic registries

- Updating is linked with processes where information originates

- $\quad$ The NTDB supports 3D and 4D

- Quality is managed

- Co-operation is a key

- Existing data is used and linked to the system

- Data is open but also data protection is maintained for sensitive and personal data

- New system should introduce return on investment (ROI)

- Use on public safety has a high priority.

As a starting point three projects within the programme were initiated. The first project is a pilot project on buildings. There we will demonstrate the whole process from data collection to data use. In this project open source solutions have a priority. The second project is defining new data quality management process for the NTDB and the third project was defining the persistent IDs. In beginning of 2016 five new pilot projects were initiated. These will pilot the persistent IDs, generalisation between NTDB City and Topo layers, automation of production using laser scanned and other remote sensing data, use of UAV and mobile production for the NTDB City and crowd sourcing. In addition we are now building the common data model, processes (business and technical) and the technical architecture. During 2017-2018 implementation of the new system will be completed.

\subsection{Content}

Figure 1 depicts the planned content for the NTDB. The principal idea is that the NTDB builds the basic location reference connecting to other basic registers which maintain attribute information. Connection to the thematic information is looser offering still the basic reference.

Themes we are considering to include are

- Hydrography

- $\quad$ Land Cover/Land use

- $\quad$ Buildings

- $\quad$ Road addresses

- Transportation network

- $\quad$ Pipelines and electrical network

- Governmental Facilities (schools and hospitals)

Strongly linked themes include

- $\quad$ Building data and addresses (maintained by the Population Register Centre)

- $\quad$ Public road attributes (maintained by the Road Authority)

- Hydrology (maintained by the Finnish Environment Institute)

- Land Use (maintained by the Finnish Environment Institute)

- $\quad$ Protected Sites (maintained by the Finnish Enviroment Instute and other agencies)

- $\quad$ Cadastral Parcels (maintained by the NLS)

- $\quad$ Administrative Units (maintained by the NLS)

- Planning information (maintained by municipalities)

- $\quad$ Land Parcels (maintained by Agency for Rural Affairs)

- $\quad$ Forestry (maintained by Forest Centre).

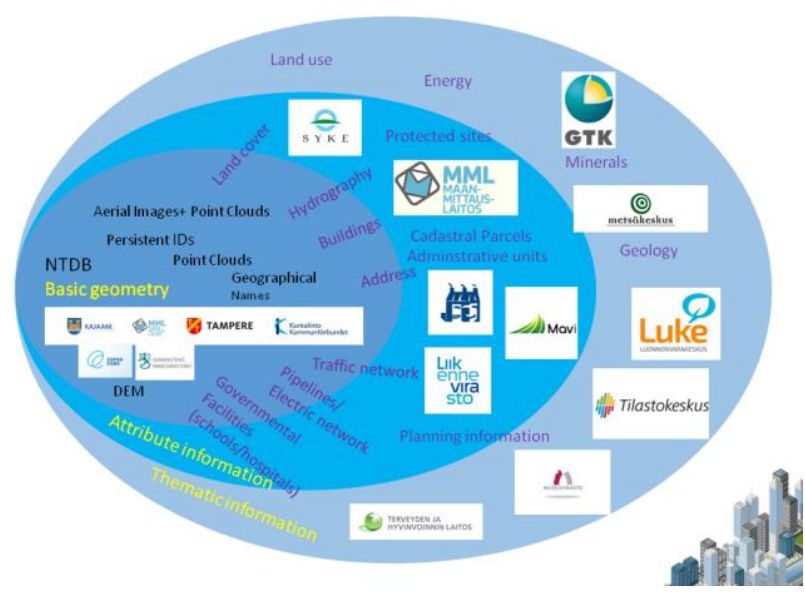

Figure 1. Content of the NTDB and connections with other governmental agencies and data 


\subsection{Level of details in Features and Geographical Areas}

For feature level of details (LoD) we plan to utilise the CityGML classification. The basic idea on level of details is as follows:

- Class A: A city centre, features are represented in LoD2 (or better if available from plans).

- Class B: Other densely populated area or industrial area, features are represented in LoD2. Class B may also contain shore areas with recreational activities.

- $\quad$ Class C: Other area, features are represented in LoD1 or LoD2

The class $\mathrm{A}$ and $\mathrm{B}$ areas should have data from the municipalities and class $\mathrm{C}$ areas are coming from the NLS.

\subsection{Division of work}

National Land Survey goal is to stop duplication of work. If a municipality is keeping its basic geographical information upto-date then the NTDB incorporate this data. There is a possibility that an agreement on cost sharing is agreed between a municipality and the NLS in some areas of maintenance (e.g. laser scanning)

National Land Survey does a lot of co-operation with other public administration organizations. Here we also want to avoid duplication of work. One already achieved example is the National Aerial Imaging Programme (NLS, 2015) agreed between the NLS, the Finnish Forest Centre and the Agency for Rural Affairs.

\section{TECHNICAL ARCHITECTURE}

As the project is in the beginning we only have draft technical architecture available. Figure 2 illustrates the basic principles. The existing NLS's TDB maintenance environment will be continued at least until 2020. It will be used for periodical updating of the NTDB. For the municipalities two options are offered. They may utilize the NTDB directly with an editing interface or they may create an interface using they own GIS solution. Number of modules needed for the NTDB has also been identified. These modules include:

- Plan: Management of schemas and data models

- Edit: Editing, including a 3D Edit

- Validate: Validating a schema

- Coordinate Transformation: Co-ordinate transformation (local to national)

- Schema Transformation: Schema transformation service

- Quality: Validating data quality

- Change: Change management (if persistent ID is not managed)

- Synchronisation: Changes updated to and from the NTDB with changes log and persistent ID

- Publish: publishing products

- Generalisation: Making a generalisation between layers

- User Feedback: Management of feedback

- Process management: Management of processes

- API: Application Programming Interface

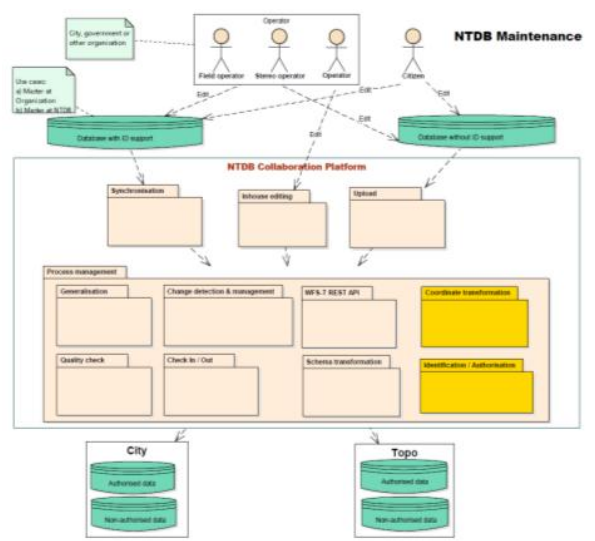

Figure 2. Technical Architecture of the NTDB

The preference is towards open source modules if available.

\section{CONCLUSIONS}

Similar initiatives are already implemented in Netherlands, Denmark, Sweden, Switzerland and Norway. The European Location Framework project (Jakobsson, 2012) has developed many concepts and modules that will be utilized in this national development project. For example quality gatekeeper concept, quality rules, generalisation, edge matching and change detection tools will be utilized. National Topographic Database will create an open collaboration platform building a key component for the Finnish National Spatial Data Infrastructure.

\section{REFERENCES}

Ahonen-Rainio, P., Mäkelä J., Virrantaus, K., 2014. Menetelmä avoimen maastotiedon vaikuttavuuden arvioimiseksi. ("Method to evaluate value of the open topographic data").

http://www.maanmittauslaitos.fi/sites/default/files/aalto maastot ietojen_vaikuttavuus_tutkimus2014.pdf.

Jakobsson, A., 2006. On the Future of Topographic Base Information Management in Finland and Europe. Doctoral dissertation. Helsinki University of Technology,

http://lib.tkk.fi/Diss/2006/isbn9512282062/,180 p +annexes.

Jakobsson, A., 2012. Introducing a New Paradigm for Provision of European Reference Geo-Information - Case Study of the European Location Framework Concept, In: Jobst M. (ed.), Service Oriented Mapping 2012, JOBST Media Präsentation Management Verlag. Wien 2012, pp. 51-62.

Kilpeläinen, T. 1997. Multiple Representation and Generalization of Geo-Databases for Topographic Maps. Doctoral dissertation, Helsinki University of Technology.Publications of the Finnish Geodetic Institute, N:o 124, Kirkkonummi, 229 p.

MMM, 2015. Ministry of Agriculture and Forestry: Report of Topographic database 2030 . 
http://mmm.fi/documents/1410837/1801204/Maastotietojarjeste lma_2030_-selvitys_Loppuraportti_28.2.2015.pdf.

Mäkelä, J., 2014. Presentation in INSPIRE conference 2014, Aalborg, Denmark

http://inspire.ec.europa.eu/events/conferences/inspire_2014/pdf s/19.06_3_14.00_Jaana_M\%C3\%A4kel\%C3\%A4.pdf.

NLS, 2015. Kansallinen kuvausohjelma ("National Aerial Image Programme").

http://www.maanmittauslaitos.fi/ammattilaisille/maastotiedot/ka ukokartoitus/ilmakuvat/kansallinen-kuvausohjelma. 